\title{
Farinha de banana verde não altera perfil lipídico e inflamatório de mulheres com excesso de peso
} Green banana flour does not alter lipid and inflammatory profile of women overweight

\begin{abstract}
Resumo
A prevalência de doenças crônicas não transmissíveis, como as dislipidemias, o excesso de peso e as complicações relacionadas ao estado inflamatório têm aumentado em todo o mundo. Neste cenário, produtos alimentícios com alegações benéficas no tratamento e/ou prevenção destas condições surgem como promessas, muitas vezes, sem respaldo científico. A farinha de banana verde (FBV) tem ganhado espaço na mídia como uma possível promotora de efeitos positivos à saúde, mas não existem estudos controlados sobre seus reais efeitos em humanos. O objetivo deste trabalho foi analisar os impactos do consumo da FBV no peso corporal, perfil lipídico, parâmetros inflamatórios e no consumo alimentar de mulheres adultas com excesso de peso. Foi realizado um estudo de intervenção no qual 25 mulheres adultas com excesso de peso consumiram, diariamente, $20 \mathrm{~g}$ de FBV, durante 45 dias. O protocolo do estudo incluiu avaliações antropométricas, de composição corporal, consumo alimentar, perfil lipídico e determinação de parâmetros inflamatórios séricos. A idade média das participantes foi 34 anos, com Índice de Massa Corporal médio de $27,7 \mathrm{~kg} / \mathrm{m}^{2}$. O consumo da FBV não alterou o peso, a composição corporal, o perfil lipídico e os parâmetros inflamatórios. Houve aumento na ingestão de fibras (variação no consumo mediano de 12,72g para 14,16g; $\mathrm{p}=0,031$ ), embora a necessidade nutricional deste nutriente não tenha sido alcançada ( $25 \mathrm{~g} / \mathrm{dia})$. O consumo isolado da FBV não promoveu alterações corporais e metabólicas significativas. A adoção de medidas isoladas oferece efeitos limitados e deve ser desencorajada como única forma de melhora da saúde.
\end{abstract}

Palavras-chave: Peso Corporal. Musa. Fibras na Dieta. Inflamação. Lipídeos.

\begin{abstract}
The prevalence of chronic diseases such as dyslipidemia, overweight and complications related to the inflammatory state have increased worldwide. In this scenario, food products which claim to be beneficial in the treatment and/or prevention of these conditions arise as promises often having no scientific support. The green banana flour (GBF) has gained media attention as a possible promoter of beneficial health effects. However, there are no controlled studies on their real effects in human studies. The objective of this study was to analyze the effects of consumption of GBF in body weight, lipid profile, inflammatory parameters and food consumption in adult overweight women. An intervention study in which 25 adult overweight women consumed daily $20 \mathrm{~g}$ of GBF during 45 days was carried out. The study protocol included anthropometric measurements, body composition, food intake, lipid profile and determination of serum inflammatory parameters. The mean age of participants was 34 years, with Body Mass Index of $27.7 \mathrm{~kg} / \mathrm{m}^{2}$. The consumption of FBV did not alter weight, body composition, lipid profile and inflammatory parameters. There was an increase in fiber intake (variation in median intake of $12,72 \mathrm{~g}$ to $14,16 \mathrm{~g} ; \mathrm{p}=0,031)$, although it has not achieved the needs of this nutrient ( $25 \mathrm{~g} /$ day). Isolated consumption of FBV did not cause significant bodily and metabolic changes. The adoption of individual measures offer limited effects and should be discouraged as the only way of improving health.
\end{abstract}

Keywords: Body Weight. Musa. Dietary Fiber. Inflammation. Lipids.

DOI: 10.15343/0104-7809.20153902174181

* Departamento de Nutrição e Saúde. Universidade Federal de Viçosa, Minas Gerais, Brasil. E-mail: sandratavs@hotmail.com

** Departamento de Nutrição e Saúde. Universidade Federal de Viçosa, Minas Gerais, Brasil.

Os autores declaram não haver conflito de interesses. 


\section{INTRODUÇÃO}

O excesso de peso e as doenças crônicas não transmissíveis são condições cada vez mais frequentes em todo o mundo. Estima-se que, no Brasil, se a prevalência de excesso de peso continuar no mesmo ritmo, em 2022, 65,2\% e $24,8 \%$ dos adultos apresentarão sobrepeso e obesidade, respectivamente ${ }^{1}$. O desequilíbrio no consumo de macronutrientes está entre as principais causas e a obesidade tem sido estudada como um estado inflamatório crônico associado a diversas condições patológicas, como as doenças cardiovasculares².

De um modo geral, a base fisiopatológica para os eventos cardiovasculares é a aterosclerose, caracterizada como um processo inflamatório crônico da parede vascular com elevação de marcadores inflamatórios séricos ${ }^{3}$. As dislipidemias são caracterizadas por alterações no metabolismo lipídico e resultam na elevação do colesterol e/ou triglicérides, assumindo importante papel no desencadeamento da gênese da aterosclerose e das doenças cardiovasculares ${ }^{4}$. O tratamento não medicamentoso de tais condições exige mudanças alimentares e no estilo de vida, que devem ser adotadas de forma contínua e a longo prazo.

A busca por formas alternativas para a rápida perda de peso e melhora da saúde é crescente, sendo promovida por meios de comunicação que divulgam informações, muitas vezes, sem respaldo científico. A farinha de banana verde (FBV) tem ganhado espaço na mídia não científica como uma possível promotora de efeitos benéficos à saúde. As possíveis alegações do consumo da FBV veiculadas incluem redução do apetite, emagrecimento, melhora do perfil lipídico, retardo do envelhecimento, prevenção de câncer e cardiopatias (Quadro 1). A busca por tais benefícios atrai consumidores que incorporam sua utilização de forma indiscriminada e como medida isolada para promoção e melhora da saúde.

Quadro 1. Alegações benéficas da farinha de banana verde (FBV) para a saúde publicadas pela mídia. São Paulo-SP.

\begin{tabular}{|c|c|c|c|}
\hline Mídia & $\begin{array}{c}\text { Data da } \\
\text { publicação }\end{array}$ & Título da Matéria & Alegação da FBV \\
\hline Globo Repórter & 10/10/2008 & $\begin{array}{l}\text { Farinha de banana verde é } \\
\text { esperança para diabéticos }\end{array}$ & $\begin{array}{l}\text { Prevenção do câncer de intestino } \\
\text { Evita o aumento da glicemia }\end{array}$ \\
\hline Portal Ruy Gripp & 05/05/2009 & $\begin{array}{l}\text { Banana: Verde, Emagrece } \\
\text { e Madura, Engorda }\end{array}$ & $\begin{array}{l}\text { Emagrecimento por meio da saciedade } \\
\text { Regulação do funcionamento intestinal } \\
\text { Controle da pressão arterial } \\
\text { Prevenção do Diabetes } \\
\text { Prevenção de doenças cardiovasculares }\end{array}$ \\
\hline $\begin{array}{l}\text { Portal Dicas de } \\
\text { Mulher }\end{array}$ & 29/10/2010 & Farinha de banana verde & $\begin{array}{l}\text { Controle da glicemia } \\
\text { Prevenção de doenças cardiovasculares } \\
\text { Prevenção do câncer de intestino } \\
\text { Confere saciedade o que leva à redução de peso }\end{array}$ \\
\hline Portal Minha Vida & 13/08/2013 & $\begin{array}{l}\text { Sete benefícios da farinha } \\
\text { de banana verde para a } \\
\text { saúde }\end{array}$ & $\begin{array}{l}\text { Controla e previne o diabetes } \\
\text { Melhora o trânsito intestinal } \\
\text { Previne câncer de intestino } \\
\text { Confere saciedade o que leva à redução de peso } \\
\text { Fortalece a imunidade } \\
\text { Reduz os níveis de colesterol } \\
\text { Alivia sintomas da TPM } \\
\text { Previne a osteoporose }\end{array}$ \\
\hline Portal Tua Saúde & 03/12/2013 & Farinha de banana verde & $\begin{array}{l}\text { Emagrecimento por meio da saciedade } \\
\text { Controle do Diabetes }\end{array}$ \\
\hline $\begin{array}{l}\text { Revista Veja São } \\
\text { Paulo }\end{array}$ & 05/05/2014 & $\begin{array}{l}\text { Saiba como fazer a } \\
\text { biomassa de banana verde } \\
\text { e entenda seus benefícios }\end{array}$ & $\begin{array}{l}\text { Controle da Glicemia e do colesterol } \\
\text { Saúde intestinal }\end{array}$ \\
\hline
\end{tabular}

175 
$A$ adição da FBV às preparações incrementa o teor de fibras, proteínas, potássio, ferro, magnésio, cálcio, fósforo e sódio, além de aumentar o rendimento dos produtos ${ }^{5}$. Apresenta ainda elevado teor de amido total $(73,45 \%)$, amido resistente (AR) $(17,5 \%)$ e fibras (cerca de 14,5\%), características utilizadas para justificar seus supostos benefícios ${ }^{6}$.

Apesar de acrescentar valor nutricional às preparações ${ }^{7}$, não há na literatura, até o momento, evidências científicas da sua eficácia no tratamento do excesso de peso ou qualquer outra condição patológica. Na busca por evidências que respaldem as alegações sobre a FBV, este estudo teve o objetivo de investigar os efeitos deste produto no peso corporal, perfil lipídico e em parâmetros inflamatórios de muIheres adultas com excesso de peso. Espera-se que a inclusão da FBV contribua para a melhora significativa destes parâmetros, confirmando, assim, os efeitos esperados pelos consumidores.

\section{MÉTODOS}

O estudo foi submetido e aprovado pelo Comitê de Ética em Pesquisa com Seres Humanos da Universidade Federal de Viçosa (UFV) ( $\mathrm{n}^{\mathrm{o}}$ 147/2011) e as participantes assinaram o Termo de Consentimento Livre e Esclarecido.

\section{Sujeitos}

Participaram do estudo mulheres adultas com idade entre 20 e 45 anos e excesso de peso (Índice de Massa Corporal $\geq 25 \mathrm{~kg} / \mathrm{m}^{2}$ ). Para o cálculo amostral foi considerada perda de 2,5 $\mathrm{kg}$ de peso corporal com $\mathrm{kg}$ como desfecho ${ }^{8,9} \mathrm{e}$ 90\% de poder estatístico, que resultou em um tamanho amostral mínimo de 23 voluntárias. Considerando possíveis perdas amostrais foram selecionadas, inicialmente, 40 voluntárias e estudo foi concluído com 25 mulheres.

Os critérios de exclusão adotados foram: presença de alergia/intolerância ao alimento teste (relatada antes ou durante a execução do estudo), nível de atividade física classificado como ativo ou muito ativo pelo Questionário Internacional de Atividade Física (IPAQ), comportamento alimentar restritivo, segundo Three Factor Eating Questionnaire (TFEQ), uso de medicamentos (exceto contraceptivos orais), tabagismo, auto-relato de doenças crônico-metabólicas (diabetes mellitus, hipertensão arterial sistêmica, hipotireoidismo).

A versão curta do IPAQ, proposta pela Organização Mundial de Saúde e validada para a população brasileira, segundo Matsudo et al. $(2001)^{10}$, foi utilizada para avaliar o nível de atividade física de todas as voluntárias recrutadas, com a não inclusão das voluntárias classificadas como ativas ou muito ativas. Durante o período do estudo foi solicitado às participantes que mantivessem suas atividades físicas habituais.

O comportamento alimentar das voluntárias foi avaliado durante a fase de recrutamento por meio da aplicação do TFEQ. Por meio deste instrumento foram avaliados três aspectos do comportamento alimentar: (i) escala de restrição cognitiva, que aferiu a proibição alimentar para influenciar o peso ou a forma corporal; (ii) escala de alimentação emocional, que mediu a propensão para comer exageradamente em resposta a estados emocionais negativos e (iii) escala de descontrole alimentar, que verificou a tendência a perder o controle alimentar na presença de fome ou estímulos externos. No aspecto restrição alimentar foi adotado a pontuação > 14 como critério de exclusão visando a não inclusão de voluntárias com comportamento alimentar muito restritivo, que pudesse comprometer o consumo do alimento teste ${ }^{11}$.

A Figura 1 apresenta o fluxograma com as etapas do estudo.

\section{Consumo da Farinha de Banana Verde}

A FBV utilizada foi de uma única marca, adquirida no comércio local e porcionada em embalagens plásticas individuais contendo $20 \mathrm{~g}$. As porções foram distribuídas semanalmente, identificadas com o nome da voluntária e a data para consumo. As participantes foram orientadas a consumir a porção de FBV por 45 dias no desjejum, adicionada ao leite, iogurte ou suco de frutas. Segundo a composição nutricional detalhada no rótulo, em 100g da FBV oferecida havia 310 calorias, $65 \mathrm{~g}$ de carboidratos, $5 \mathrm{~g}$ de proteínas, 0,5g de lipídios e $11 \mathrm{~g}$ de fibras. 
Figura 1. Fluxograma do estudo. Viçosa (MG), 2013.

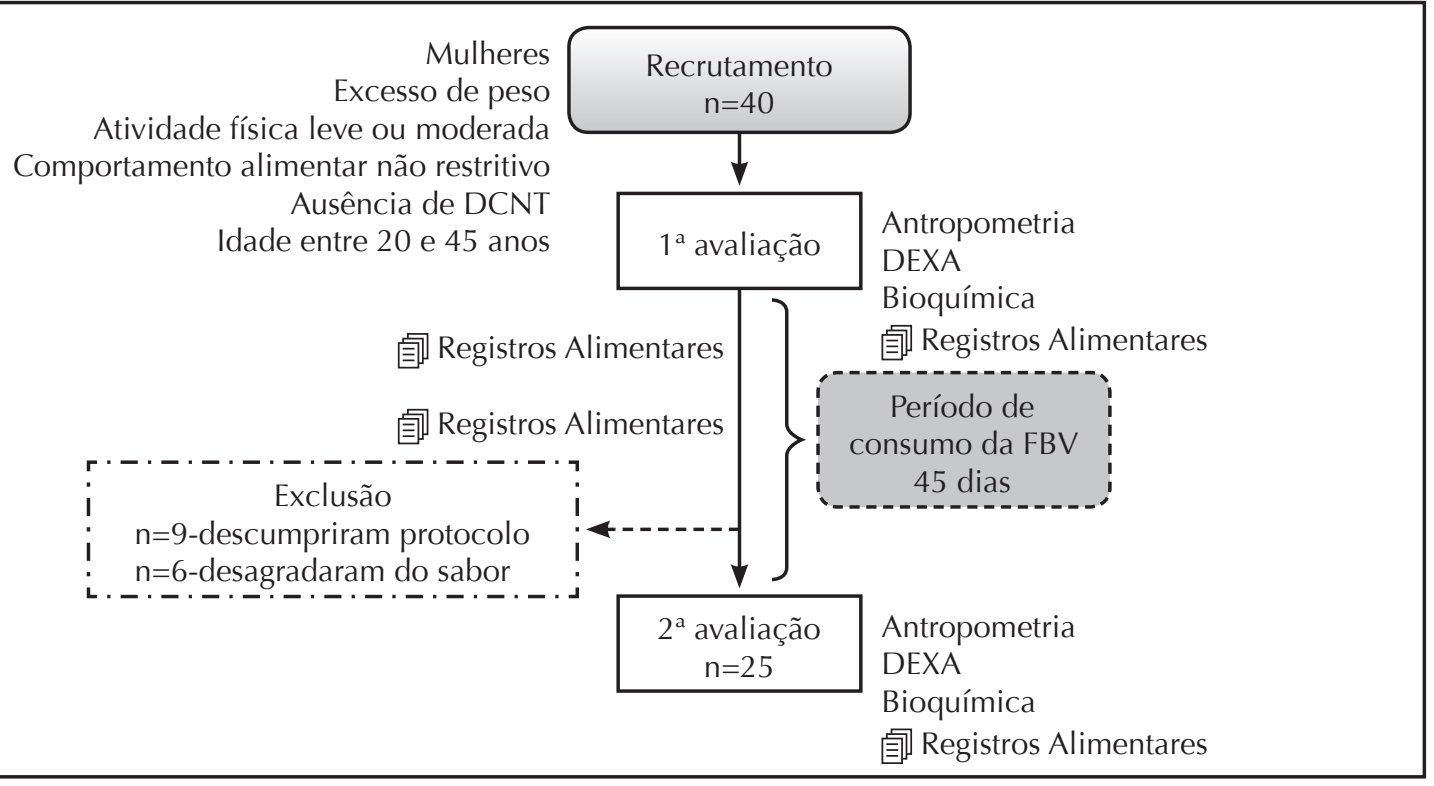

DCNT: Doenças crônicas não transmissíveis; DEXA: Radioabsormetria de Feixes Duplos; FBV: Farinha de Banana Verde.

\section{Antropometria}

A avaliação antropométrica foi realizada antes e após os 45 dias de consumo da FBV. O peso corporal em quilogramas $(\mathrm{kg})$ foi obtido em balança eletrônica digital tipo plataforma $\left(\right.$ Tanita $^{\circledR}$ ) com capacidade de $150 \mathrm{~kg}$ e precisão de 50g. A estatura foi aferida em antropômetro vertical (Alturaexata ${ }^{\circledR}$ ), segundo as recomendações de Jellife $(1968)^{12}$. A partir o peso e estatura, foi calculado o Índice de Massa Corporal (IMC).

O perímetro da cintura foi aferido na cicatriz umbilical, com fita métrica não extensível $\left(\mathrm{TBW}^{\circledR}\right)^{\circledR}$, com a voluntária de pé e após expiração completa. O percentual de gordura corporal e a massa magra foram obtidos por meio de Radioabsormetria de Feixes Duplos (Dual Energy X-Ray Absorptiometry - DEXA) (Lunar Densiometry - GE ${ }^{\circledR}$ ) com auxílio do software Encore 2010 (versão 13.3) conduzido por técnico especializado. Todas as avaliações foram realizadas pela manhã, com as participantes em jejum, após 15 minutos de repouso.

\section{Avaliação Bioquímica}

A coleta de sangue foi efetuada antes do início do consumo da FBV e ao final do experimento, no Laboratório de Análises Clínica da Divisão de
Saúde (Universidade Federal de Viçosa), com os indivíduos em jejum de 12 horas. A determinação dos níveis de triglicerídeos plasmáticos, colesterol total e frações, ácido úrico, complemento C3 e ceruloplasmina foi realizada pelo analisador bioquímico Cobas Mira Plus (Roche ${ }^{\circledR}$ ). A proteína C reativa foi avaliada por nefelometria e a presença de hidroperóxidos foi avaliada pela determinação das substâncias reativas ao ácido tiobarbitúrico (TBARS), segundo Buege e Aust (1978) ${ }^{13}$.

\section{Avaliação Dietética}

Foram utilizados registros alimentares para a avaliação do consumo alimentar. As voluntárias foram orientadas a preencher três registros em dias alternados, sendo um dia referente ao final de semana, em quatro momentos distintos do estudo: na semana anterior ao início do consumo (semana 0), na primeira (semana 1), terceira (semana 3) e sexta (semana 6) semanas de consumo da FBV (Figura 1). Os registros foram revisados na presença das voluntárias para esclarecer possíveis dúvidas e garantir maior precisão nas informações. As medidas caseiras dos alimentos ingeridos foram convertidas em gramas e a foram analisadas utilizando o software DietPro ${ }^{\circledR}$ (versão 5.0).
177 


\section{Análise dos Dados}

A normalidade das variáveis foi avaliada pelo teste Shapiro-Wilk. Os efeitos da intervenção nos parâmetros avaliados foram verificados pelo teste $t$ pareado, para variáveis com distribuição normal ou pelo teste de Wilcoxon, para variáveis que apresentaram distribuição não normal. As análises estatísticas foram realizadas significância estatística de 5\%.

\section{RESULTADOS}

Das 40 voluntárias inicialmente recrutadas, 25 completaram o protocolo do estudo. A idade banana verde ( $n=25)$. Viçosa, 2013. média das participantes foi 34 anos (DP: 7,8), com IMC médio de 27,7kg/m² (DP: 1,78).

Em relação à ingestão alimentar, não houve diferença na ingestão calórica e no consumo de carboidratos, proteínas e lipídios totais nos diferentes momentos do estudo (Semana 0, Semana 1, Semana 3 e Semana 6). Foi identificada redução no consumo de lipídeos poli-insaturados e aumento no consumo médio de fibras (Tabela 1). No entanto, mesmo com o maior consumo de fibras na dieta causado pela inclusão da FBV, o valor médio de ingestão não atingiu a recomendação nutricional diária de $25 \mathrm{~g}$ para mulheres de 19 a 50 anos $^{14}$.

Tabela 1. Ingestão calórica e de nutrientes das voluntárias antes e durante o consumo da farinha de

\begin{tabular}{|c|c|c|c|c|c|c|}
\hline \multirow{2}{*}{ Ingestão dietética } & Semana $0^{a}$ & Semana $1^{b}$ & Semana $^{c}$ & Semana $6^{d}$ & \multirow{2}{*}{ Pe } & \multirow{2}{*}{$\mathbf{P f}^{\mathrm{f}}$} \\
\hline & \multicolumn{4}{|c|}{ Mediana (mínimo- máximo) } & & \\
\hline Energia (kcal) & $\begin{array}{c}1792,83 \\
(1144,11-3774,71)\end{array}$ & $\begin{array}{c}1776,82 \\
(755,53-2781,69)\end{array}$ & $\begin{array}{c}1635,22 \\
(1015,48-2613,52)\end{array}$ & $\begin{array}{c}1692,59 \\
(945,19-3696,13)\end{array}$ & 0,119 & 0,158 \\
\hline Carboidrato (g) & $\begin{array}{c}216,05 \\
(138,54-583,44)\end{array}$ & $\begin{array}{c}225,50 \\
(92,84-375,65)\end{array}$ & $\begin{array}{c}216,49 \\
(130,62-350,37)\end{array}$ & $\begin{array}{c}204,09 \\
(111,62-453,64)\end{array}$ & 0,100 & 0,192 \\
\hline Proteína (g) & $\begin{array}{c}65,01 \\
(32,97-101,30)\end{array}$ & $\begin{array}{c}67,94 \\
(32,24-113,59)\end{array}$ & $\begin{array}{c}61,84 \\
(39,78-83,67)\end{array}$ & $\begin{array}{c}60,80 \\
(39,74-132,49)\end{array}$ & 0,074 & 0,443 \\
\hline Lipídios (g) & $\begin{array}{c}68,65 \\
(28,64-123,89)\end{array}$ & $\begin{array}{c}65,65 \\
(27,44-130,22)\end{array}$ & $\begin{array}{c}59,62 \\
(29,30-118,68)\end{array}$ & $\begin{array}{c}64,82 \\
(23,00-134,07)\end{array}$ & 0,059 & 0,132 \\
\hline $\begin{array}{l}\text { Ácidos Graxos } \\
\text { Monoinsaturados (g) }\end{array}$ & $\begin{array}{c}14,06 \\
(5,79-29,82)\end{array}$ & $\begin{array}{c}13,95 \\
(5,44-52,80)\end{array}$ & $\begin{array}{c}16,33 \\
(5,73-26,30)\end{array}$ & $\begin{array}{c}14,76 \\
(4,63-31,66)\end{array}$ & 0,532 & 0,276 \\
\hline $\begin{array}{l}\text { Ácidos Graxos } \\
\text { Poli-insaturados (g) }\end{array}$ & $\begin{array}{c}10,51 \\
(3,21-29,12)\end{array}$ & $\begin{array}{c}9,53 \\
(3,98-49,48)\end{array}$ & $\begin{array}{c}8,36 \\
(5,06-19,53)\end{array}$ & $\begin{array}{c}8,32 \\
(1,81-25,57)\end{array}$ & 0,410 & 0,042 \\
\hline $\begin{array}{l}\text { Ácidos Graxos } \\
\text { Saturados (g) }\end{array}$ & $\begin{array}{c}17,37 \\
(6,64-33,88)\end{array}$ & $\begin{array}{c}17,85 \\
(9,72-1049,25)\end{array}$ & $\begin{array}{c}19,44 \\
(8,03-39,57)\end{array}$ & $\begin{array}{c}19,37 \\
(6,89-42,48)\end{array}$ & 0,801 & 0,288 \\
\hline Colesterol (mg) & $\begin{array}{c}185,34 \\
(78,27-520,43)\end{array}$ & $\begin{array}{c}192,50 \\
(49,14-382,18)\end{array}$ & $\begin{array}{c}190,01 \\
(106,67-383,62)\end{array}$ & $\begin{array}{c}171,63 \\
(45,96-512,58)\end{array}$ & 0,968 & 0,968 \\
\hline Fibra (g) & $\begin{array}{c}12,72 \\
(4,39-30,60)\end{array}$ & $\begin{array}{c}14,15 \\
(8,38-49,91)\end{array}$ & $\begin{array}{c}12,88 \\
(9,01-24,31)\end{array}$ & $\begin{array}{c}14,16 \\
(7,85-33,55)\end{array}$ & 0,033 & 0,031 \\
\hline
\end{tabular}

${ }^{a}$ Ingestão dietética na semana anterior ao consumo da farinha de banana verde.

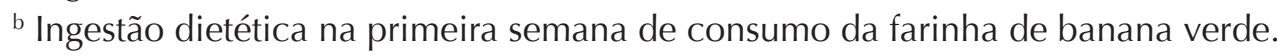

c Ingestão dietética na quarta semana de consumo da farinha de banana verde.

d Ingestão dietética na última semana de consumo da farinha de banana verde.

e Teste de Friedman.

f Teste de Wilcoxon comparando a "Semana 0" com a "Semana 1" (para o conteúdo energético por refeição) e comparando a "Semana 0" com a "Semana 6" (para os demais nutrientes). 
Tabela 2. Antropometria, composição corporal, perfil lipídico e parâmetros inflamatórios antes e após o consumo da farinha de banana verde ( $\mathrm{n}=25)$. Viçosa, 2013.

\begin{tabular}{|c|c|c|c|c|c|}
\hline \multirow[b]{2}{*}{ Parâmetro } & \multicolumn{2}{|c|}{ Inicial $\left(T_{0}\right)$} & \multicolumn{2}{|c|}{ Final $\left(T_{45}\right)$} & \multirow{2}{*}{$\mathbf{P}$} \\
\hline & Média (DP) & Mediana (Min-Máx) & Média (DP) & Mediana (Min-Máx) & \\
\hline Peso (kg) & $72,86(6,97)$ & $71,70(59,75-87,10)$ & $72,81(6,75)$ & $72,00(59,25-86,80)$ & $0,851^{\mathrm{a}}$ \\
\hline Altura (m) & $1,61(0,05)$ & $1,62(1,51-1,71)$ & $1,62(0,05)$ & $1,62(1,51-1,71)$ & $0,273^{b}$ \\
\hline IMC $\left(\mathrm{kg} / \mathrm{m}^{2}\right)$ & $27,72(1,78)$ & $27,40(25,15-31,34)$ & $27,67(1,67)$ & $27,47(25,13-31,15)$ & $0,619^{b}$ \\
\hline $\mathrm{PC}(\mathrm{cm})$ & $94,00(7,24)$ & $96,00(77,80-105,00)$ & $94,31(6,66)$ & $95,50(78,00-105,00)$ & $0,408^{b}$ \\
\hline Gordura corporal (\%) & $40,77(4,98)$ & $42,00(30,90-51,60)$ & $40,84(5,05)$ & $41,80(32,00-49,40)$ & $0,819^{a}$ \\
\hline Massa magra (kg) & $40,31(3,35)$ & $41,21(33,21-46,60)$ & $40,26(2,93)$ & $40,93(33,42-45,38)$ & $0,837^{a}$ \\
\hline CT $(\mathrm{mg} / \mathrm{dL})$ & $175,36(31,85)$ & $173,0(103,0-245,0)$ & $179,46(28,06)$ & $180(119,0-242,0)$ & $0,334^{\mathrm{a}}$ \\
\hline $\mathrm{cHDL}(\mathrm{mg} / \mathrm{dL})$ & $45,16(8,96)$ & $44,0(31,0-68,0)$ & $45,79(10,44)$ & $45,0(32,0-77,0)$ & $0,747^{b}$ \\
\hline cLDL (mg/dL) & $106,93(26,51)$ & $109,0(37,0-164,0)$ & $109,82(26,57)$ & $109,8(39,0-156,0)$ & $0,257^{\mathrm{a}}$ \\
\hline TAG (mg/dL) & $116,36(63,37)$ & $94,0(53,0-312,0)$ & $119,28(50,82)$ & $110,0(51,0-239,0)$ & $0,597^{b}$ \\
\hline $\mathrm{AU}(\mathrm{mg} / \mathrm{dL})$ & $3,1(0,71)$ & $2,9(2,0-5,0)$ & $3,11(1,07)$ & $2,9(2,0-6,0)$ & $0,831^{b}$ \\
\hline $\mathrm{CP}(\mathrm{mg} / \mathrm{dL})$ & $36,53(9,32)$ & $33,8(25,0-58,0)$ & $37,31(12,5)$ & $34,8(23,0-73,0)$ & $0,989 b$ \\
\hline C3 (mg/dL) & $137,98(17,68)$ & $134,7(99,0-193,0)$ & $134,64(26,18)$ & $129,9(90,0-197,0)$ & $0,397^{a}$ \\
\hline PCR $(\mathrm{mg} / \mathrm{dL})^{*}$ & $3,15(3,14)$ & $2,80(0,0-9,9)$ & $2,69(3,81)$ & $1,00(0,0-13,7)$ & $0,503^{a}$ \\
\hline TBARS(nmol/mL)** & $0,83(0,26)$ & $0,82(0,39-1,5)$ & $0,67(0,32)$ & $0,66(0,0-1,12)$ & $0,087^{a}$ \\
\hline
\end{tabular}

DP: desvio-padrão; Min: mínimo; Máx: máximo; IMC: Índice de Massa Corporal; PC: perímetro da cintura; DEXA: Dual-energy X-rayabsorptiometry; CT: colesterol total; cHDL: HDL-colesterol; cLDL: LDL-colesterol; TAG: triacilglicerol; AU: ácido úrico; CP: ceruloplasmina; C3: complemento C3; PCR*: proteína C reativa $(\mathrm{n}=15) ; * *$ TBARS: $(\mathrm{n}=23)$.

aTeste t pareado

bTeste de Wilcoxon

O consumo da FBV não alterou as medidas antropométricas, de composição corporal, o perfil lipídico e os parâmetros inflamatórios (Tabela 2).

\section{DISCUSSÃO}

O consumo de $20 \mathrm{~g}$ de FBV, durante 45 dias, não alterou a antropometria, a composição corporal, os parâmetros lipídicos e inflamatórios de mulheres adultas com excesso de peso, ainda que tenha elevado o teor de fibras da dieta.

Das 40 voluntárias recrutadas, apenas 25 completaram o protocolo do estudo, indicando baixa adesão e difícil aceitabilidade do produto. Segundo o relato das voluntárias, ocorreram respostas fisiológicas diversas, variando de constipação $(n=4)$ à melhora do funcionamento intestinal $(n=6)$. Não foram encontrados na literatura trabalhos que avaliassem as implicações clínicas do consumo da FBV, o que impossibilita comparações e aponta a necessidade de mais investigações sobre este produto.

As fibras consumidas em uma dieta rica em frutas, verduras, legumes e cereais integrais contribuem para redução de peso corporal e normalização do perfil lipídico ${ }^{15}$ o que, possivelmente, melhoraria os parâmetros inflamatórios. Ma et al. (2008) ${ }^{16}$ avaliaram a relação entre consumo de fibras e os níveis plasmáticos de parâmetros inflamatórios e identificaram relação
179 
inversa entre a ingestão de fibras e valores de IL-6 e de TNF $\alpha$, associação não observada para as concentrações de PCR. Sabe-se que os efeitos das fibras dependem de suas características, da quantidade consumida e de interações que ocorrem no estômago e no intestino delgado ${ }^{15}$. $\mathrm{O}$ consumo de fibras inferior às necessidades diárias, mesmo após o aumento proporcionado pela inclusão da FBV, possivelmente limitou impactos significativos nas variáveis avaliadas.

O consumo de carboidratos não digeríveis, como o AR (presente na FBV), pode levar à mudança na atividade fermentativa ${ }^{17}$ e à efeitos benéficos na modulação da microbiota, a qual poderá contribuir para o tratamento futuro do excesso de peso e da obesidade ${ }^{18}$. Em um estudo realizado com 12 indivíduos consumindo dietas com 5,7\% de carboidratos na forma de AR não foi identificada alteração nos valores de triglicerídeos sanguíneos, mas houve aumento da oxidação lipídica (mensurada por calorimetria indireta), sugerindo uma importante atuação deste componente da dieta na prevenção da acumulação de lipídeos a longo prazo ${ }^{19}$. Em um estudo experimental, animais alimentados com dieta rica em gordura apresentaram aumento nos marcadores inflamatórios, que reduziram após consumo de diferentes tipos de fibra solúvel ${ }^{20}$.

Em relação ao consumo energético e de macronutrientes, não foram identificadas alterações após a inclusão da FBV. Como possível limitação do estudo, destacamos que a composição da FBV foi obtida a partir da informação nutricional disponível no rótulo. Não foram realizadas avaliações bromatológicas para confirmar os teores informados pelo fabricante. Sugere-se que esta avaliação seja incluída em trabalhos futuros.

No presente estudo, a inclusão de fibras não associada à redução do consumo calórico não foi capaz de promover alterações relevantes, o que corrobora a importância da restrição calórica para que sejam observados impactos significativos. Os efeitos da restrição calórica no perfil inflamatório foram demonstrados em diferentes grupos. Em um estudo com idosos com excesso de peso submetidos a dieta restrita em calorias, foi identificada redução no peso corporal acompanhada por diminuição nos valores de de PCR e Interleucina- $6^{21}$. Outro trabalho, realizado com mulheres na pré-menopausa com excesso de peso, verificou melhora no stress oxidativo após restrição calórica moderada (25\%) por 28 dias, com redução do peso e da gordura corpo$\mathrm{ral}^{22}$. Destaca-se que medidas isoladas, como a inclusão de um único alimento, não associada a modificações comportamentais e de estilo de vida são insuficientes para melhoras significativas e sustentáveis a longo prazo ${ }^{24}$. Conforme as Diretrizes Brasileiras de Obesidade ${ }^{23}$, o tratamento dietético é mais bem-sucedido quando aliado ao aumento no gasto energético e a um programa de modificação comportamental, com modificações na alimentação para toda a vida, planejamento alimentar flexível com educação alimentar, além de medidas como a prática regular de atividade física e abandono do tabagismo.

Os efeitos alegados pela mídia não foram observados no presente estudo. Marins et al. $(2011)^{24}$ destacam que as mensagens sobre alimentação veiculadas nos meios de comunicação merecem atenção, uma vez que exercem papel fundamental na aquisição de novos hábitos alimentares. O estímulo da mídia ao consumo de produtos/alimentos com alegações terapêuticas e/ou profiláticas sem comprovação científica deve ser alvo de fiscalização e ações de órgãos públicos de saúde, especialmente quanto a enfatizar que não há resultados efetivos na ausência de mudanças significativas de hábitos.

Assim, a abordagem de doenças crônicas requer uma ação em diversos aspectos, e, em relação à alimentação, várias modificações podem ser necessárias para que se observe, de fato, melhora significativa da saúde.

\section{CONCLUSÃO}

O consumo de $20 \mathrm{~g}$ de FBV por mulheres adultas com excesso de peso, durante 45 dias, não promoveu melhora nos parâmetros antropométricos, de composição corporal, de perfil lipídico e nos marcadores inflamatórios. Foi identificado aumento no consumo de fibras, mas, ainda assim, as recomendações nutricionais para estes nutrientes não foram alcançadas. 


\section{REFERÊNCIAS}

1. Brasil. Ministério da Saúde. Secretaria de Vigilância em Saúde. Departamento de Análise de Situação de Saúde. Plano de ações estratégicas para o enfrentamento das doenças crônicas não transmissíveis (DCNT) no Brasil 2011-2022. Brasília: Ministério da Saúde; 2011.

2. Lopes HF. Hipertensão e inflamação: papel da obesidade. Rev Bras Hipertens. 2007;14(4):239-44.

3. Santos RD, Gagliardi ACM, Xavier HT, Magnoni CD, Cassani R, Lottenberg AM, et al. Sociedade Brasileira de Cardiologia. I Diretriz sobre o consumo de gorduras e saúde cardiovascular. Arq Bras Cardiol. 2013;100(1 Supl 3):1-40.

4. Lottenberg AMP, Buonacorso V. Dislipidemias. In: Cuppari L. Nutrição nas doenças crônicas não-transmissíveis. Barueri,SP: Manole; 2009. p. 191-217.

5. Izidoro DR, Scheer AP, Negre MFO, Haminiuk CWI, Sierakowski MR. Avaliação físico-química, colorimétrica e aceitação sensorial de emulsão estabilizada com polpa de banana verde. Rev Inst Adolfo Lutz. 2008;67(3):167-76.

6. Saifullah R, Abbas FMA, Yeoh SY, Azhar ME. Utilization of green banana flour as a functional ingredient in yellow noodle. Int Food Res J. 2009;16:373-79.

7. Fasolin LH, Almeida GC, Castanho OS, Netto-Oliveira ER: Biscoitos produzidos com farinha de banana: avaliações química, física e sensorial. Ciênc Tecnol Aliment. 2007; 27(3):524-9.

8. Saltzman E, Moriguti JC, Das SK, Corrales A, Fuss P, Greenberg AS et al. Effects of a cereal rich in soluble fiber on body composition and dietary compliance during consumption of a hypocaloric diet. J Am Coll Nutr. 2001;20(1):50-7.

9. Weyne GRS. Determinação do tamanho da amostra em pesquisas experimentais na área de saúde. Arq Méd ABC. 2004;29(2):87-90.

10. Matsudo SMM, Araújo T, Marsudo V, Andrade D, Andrade E, Oliveira LC, et al. Questionário internacional de atividade física (IPAQ): estudo de validade e reprodutibilidade no Brasil. Rev Bras Ativ Fís Saúde. 2001;6(2):5-18.

11. Stunkard AJ, Messick S. The Three Factor Eating Questionnaire to measure dietary restraint, disinhibition and hunger. J Psychosom Res. 1985;29(1):71-83.

12. Jelliffe, DB. Evaluación del estado de nutrición de la comunidad com especial referencia a las encuestas en las regiones em desarrollo. Genebra: Organización Mundial de la Salud. 1968. 291p.

13. Buege JA, Aust SD. Microsomal lipid peroxidation. Methods Enzymol. 1978;52:302-10.

14. Washington DC. Dietary Reference Intakes for Calcium and Vitamin D. A Report of the Panel on Macronutrients, Subcommittees on Upper Reference Levels of Nutrients and Interpretation and Uses of Dietary Reference Intakes, Standing Committee on the Scientific Evaluation of Dietary Reference Intakes. "Summary Tables, Dietary Reference Intakes." Dietary Reference Intakes for Energy, Carbohydrate, Fiber, Fat, Fatty Acids, Cholesterol, Protein, and Amino Acids (Macronutrients). The National Academies Press 2005. Disponível em: http://www.nal.usda.gov/fnic/DRI/DRI_Energy/energy_full_report.pdf. 15. Colli C, Sardinha F, Filisetti TMCC. Alimentos Funcionais. In: Cuppari L. Guias de Medicina Ambulatorial e Hospitalar - Nutrição Clínica no Adulto. $2^{a}$ ed. Barueri, SP: Manole; 2005. p.71-87.

16. Ma Y, Hébert JR, Li W, Bertone-Johnson ER, Olendzki B, Pagoto SL, et al. Association between dietary fiber and markers of systemic inflammation in the Women's Health Initiative Observational Study. Nutrition. 2008;24:941-9.

17. Langkilde AM, CHAMP M, ANDERSON H. Effects of high-resistant starch banana flour (RS2) on in vitro fermentation and small- bowel excretion of energy, nutrients and sterols: an ileostomy study. Am J Clin Nutr. 2002;75(1):104-11.

18. Silva ST, Santos CA, Bressan J. Intestinal microbiota: relevance to obesity and modulation by prebiotics and probiotics. Nutr Hosp. 2013;28(4):1039-48.

19. Higgins JA, Higbee DR, Donahoo WT, Brown IL, Bell ML, Bessesen DH. Resistant starch consumption promotes lipid oxidation. Nutr Metab. 2004;1(1):8.

20. Sánchez D, Quiñones M, Moulay L, Muguerza B, Miguel M, Aleixandre A. Soluble fiber-enriched diets improve inflammation and oxidative stress biomarkers in Zucker fatty rats. Pharmacol Res. 2011;64(1):31-5.

21. Nicklas BJ, Ambrosius W, Messier SP, Miller GD, Penninx BWJH, Loeser RF et al. Diet-induced weight loss, exercise, and chronic inflammation in older, obese adults: a randomized controlled clinical trial. Am J Clin Nutr. 2004;79(4): 544-51. 22. Buchowski MS, Hongu N, Acra S, Wang L, Warolin J, Roberts LJ. Effect of Modest Caloric Restriction on Oxidative Stress in Women, a Randomized Trial. PLoS ONE. 2012;7(10):e47079.

23. ABESO. Associação Brasileira para o Estudo da Obesidade e da Síndrome Metabólica. Diretrizes brasileiras de obesidade 2009/2010. $3^{\text {a }}$ ed. Itapevi, SP: AC Farmacêutica; 2009.

24. Marins BR, Araujo IS, Jacob SC. A propaganda de alimentos: orientação, ou apenas estímulo ao consumo? Ciênc Saúde Coletiva. 2011;16(9):3873-82.

Recebido em: 26 de maio de 2014. Aprovado em: 20 de julho de 2015. 